Marquette University

e-Publications@Marquette

$1-1-2016$

\title{
Hip External Rotator Strength Is Associated With Better Dynamic Control of the Lower Extremity During Landing Tasks
}

Philip Malloy

Marquette University, philip.malloy@marquette.edu

Alexander Morgan

Marquette University

Carolyn M. Meinerz

Marquette University

Christopher Geiser

Marquette University, christopher.geiser@marquette.edu

Kristof Kipp

Marquette University, kristof.kipp@marquette.edu

Accepted version. Journal of Strength and Conditioning Research, Vol. 30, No. 1 (January 2016):

282-291. DOI. (C) 2016 by the National Strength \& Conditioning Association. Used with permission. 


\title{
Hip External Rotator Strength Is Associated with Better Dynamic Control of the Lower Extremity During Landing Tasks
}

\author{
Philip Malloy \\ Motion and Biomechanics Analysis Laboratory, \\ Department of Physical Therapy, Program in Exercise Science, \\ Marquette University, \\ Milwaukee, WI \\ Alexander Morgan \\ Motion and Biomechanics Analysis Laboratory, \\ Department of Physical Therapy, Program in Exercise Science, \\ Marquette University, \\ Milwaukee, WI \\ Carolyn Meinerz \\ Motion and Biomechanics Analysis Laboratory, \\ Department of Physical Therapy, Program in Exercise Science, \\ Marquette University, \\ Milwaukee, WI
}




\author{
Christopher F. Geiser \\ Motion and Biomechanics Analysis Laboratory, \\ Department of Physical Therapy, Program in Exercise Science, \\ Marquette University, \\ Milwaukee, WI \\ Kristof Kipp \\ Motion and Biomechanics Analysis Laboratory, \\ Department of Physical Therapy, Program in Exercise Science, \\ Marquette University, \\ Milwaukee, WI
}

\begin{abstract}
The purpose of this study was to determine the association between hip strength and lower extremity kinematics and kinetics during unanticipated single leg landing and cutting tasks in collegiate female soccer players. Twenty-three NCAA division I female soccer players were recruited for strength testing and biomechanical analysis. Maximal isometric hip abduction and external rotation strength were measured using a hand held dynamometer and expressed as muscle torque (force $\times$ femoral length) and normalized to body weight. Three-dimensional lower extremity kinematics and kinetics were assessed with motion analysis and force plates, and an inverse dynamics approach was used to calculate net internal joint moments that were normalized to body weight. Greater hip external rotator strength was significantly associated with greater peak hip external rotation moments $(r=.47 ; p=0.021)$, greater peak knee internal rotation moments $(r=.41 ; p$ $=0.048)$, greater hip frontal plane excursion $(r=.49 ; p=0.017)$, and less knee transverse plane excursion $(r=-.56 ; p=.004)$ during unanticipated single-leg landing and cutting tasks. In addition a statistical trend was detected between hip external rotator strength and peak hip frontal plane moments $(r=.39 ; p=.06)$. The results suggest that females with greater hip external rotator strength demonstrate better dynamic control of the lower extremity during unanticipated single leg landing and cutting tasks and provide further support for the link between hip strength and lower extremity landing mechanics.
\end{abstract}

Keywords: Biomechanics, hip strength, dynamic valgus, unanticipated tasks, $A C L$ injury 
NOT THE PUBLISHED VERSION; this is the author's final, peer-reviewed manuscript. The published version may be accessed by following the link in the citation at the bottom of the page.

\section{Introduction}

Female athletes are more likely to suffer a non-contact $A C L$ injury during sports compared to male athletes. ${ }^{3}$ Despite a considerable amount of research focused on understanding the noncontact $A C L$ injury mechanism and determining the associated risk factors, the overall incidence of non-contact $A C L$ injuries in female athletes has remained high..$^{1,2}$ As part of this research focus, numerous studies have investigated lower extremity mechanics in females during sport specific tasks (e.g., landing and cutting) to better understand modifiable factors that may manifest within the non-contact ACL injury mechanism. ${ }^{11,15,23,26,29}$ These studies suggest that females exhibit movement and loading patterns that place them at a greater risk for ACL injury. In addition, these findings are supported by evidence that some of these patterns, such as greater peak external knee abduction moments and peak abduction angles, prospectively predict $A C L$ injury risk in female athletes. ${ }^{15}$ Despite the considerable amount of evidence that implicate movement and loading patterns as part of the noncontact ACL injury mechanism, it is not well understood how other aspects such as central processing, environment, and physical abilities influence biomechanical patterns during movement tasks.

Based on the fact that non-contact $A C L$ injuries occur primarily during competition where athletes have to process and respond to information under time-critical situations, researchers have designed experimental paradigms that use unanticipated tasks to study lower extremity kinematics and kinetics since these scenarios may provide better insight into movement and loading patterns that athletes would encounter during competition. ${ }^{6,8}$ When compared to anticipated tasks, lower extremity biomechanics during unanticipated tasks are consistent with kinematic and kinetic profiles known to increase the risk of ACL injury. ${ }^{6,8}$ For example, knee valgus and internal rotation moments during the stance phase of unanticipated side step cutting, jumping, and landing tasks are greater than during similar tasks under anticipated conditions. ${ }^{6,8}$ The use of unanticipated landing paradigms may therefore offer better insights into possible "worst-case scenarios" of lower extremity movement and loading patterns that one could expect to experience during a practice or game situation. ${ }^{22}$ 
In addition, it is important to gain an understanding of the influence of trainable physical abilities (e.g., muscular strength) on the lower extremity biomechanics during movement tasks, especially those tasks that are performed under time-critical situations. For example, it could be posited that hip muscle weakness could exacerbate deleterious landing kinematics and kinetics during unanticipated movement tasks as individuals would have less time to adequately control the joint motions. Indeed, practitioners and researchers commonly emphasize the role of the hip musculature in relation to lower extremity movement and loading patterns. 4,5,16,17,27,30 For example, Lawrence and colleagues (2008) found that during an anticipated single leg drop landing individuals with greater strength of the hip external rotator muscles better attenuated vertical ground reaction forces and exhibited smaller knee valgus moments than individuals with lower hip external rotator strength. ${ }^{20}$ Furthermore, in another study, individuals who demonstrated improvements in hip muscle performance after a targeted hip-strengthening intervention exhibited positive changes in lower extremity kinetics that were consistent with a lower risk for $A C L$ injury. ${ }^{30}$ Moreover, hip external rotator strength appears to be a significant predictor of the incidence of lower extremity injury risk during an entire athletic season in both males and females. ${ }^{21}$ Although these studies provide collective support for the hypothesis that hip muscle strength affects the dynamic control of the lower extremity during athletic movement tasks, it is currently not known to what extent hip strength affects dynamic kinematic and kinetic control during unanticipated single leg landing and cutting tasks.

Understanding the association between hip strength and lower extremity kinematics and kinetics is important because of the implications for biomechanical risk factors linked to the non-contact ACL injury mechanism. Practitioners could use this information to develop hip strengthening interventions that translate to improvements in landing mechanics during time-critical, game-like situations. The purpose of this study was to determine the influence of hip muscle strength on lower extremity kinematics and kinetics during unanticipated single leg landing task. We hypothesized that females with less hip abductor and external rotator strength will demonstrate movement and loading patterns that are consistent with greater risk for ACL injury.

Journal of Strength and Conditioning Research, Vol 30, No. 1 (January 2016): pg. 282-291. DOI. This article is (C) Lippincott Williams \& Wilkins, Inc. and permission has been granted for this version to appear in e-Publications@Marquette. Lippincott Williams \& Wilkins, Inc. does not grant permission for this article to be further copied/distributed or hosted elsewhere without the express permission from Lippincott Williams \& Wilkins, Inc. 
NOT THE PUBLISHED VERSION; this is the author's final, peer-reviewed manuscript. The published version may be accessed by following the link in the citation at the bottom of the page.

\section{METHODS}

\section{Experimental Approach to the Problem}

In order to study the association between hip strength and dynamic lower extremity kinematics and kinetics control during unanticipated single leg landing task, female soccer players reported to a biomechanics laboratory for movement testing and strength assessment. Maximal isometric hip abduction and external rotation torque were collected and used as the independent variables for the study. Dependent variables measured were the calculated threedimensional lower extremity kinematics and kinetics during single leg landing and cutting tasks. Statistical correlation coefficients were then used to determine the associations between the independent variables (i.e., hip abduction and external rotation torque) and the dependent variables (i.e., hip and knee excursion and peak hip and knee internal joint moments in all planes).

\section{Subjects}

An a priori power analysis (G*power software) revealed that a sample of 19 subjects would be sufficient to demonstrate a power 0.80 , at the predetermined alpha level of .05 and with a moderate effect size of 0.6 (13). Twenty-three female NCAA Division I soccer players were thus recruited for this study. The average (Mean \pm SD) age, height, and weight of the participants were $19.4 \pm 0.8$ years, $167.9 \pm 5.0$ centimeters, and $61.0 \pm 4.0$ kilograms, respectively. All participants were healthy with no history of musculoskeletal, neurologic, or cardiovascular conditions that would prevent full participation in the testing protocol. All participants completed a health history questionnaire to report injuries that occurred during previous athletic seasons. Athletes were excluded from the study if a hip, knee, or ankle injury was reported during the previous season as this may influence landing mechanics. Prior to the participation in the study, all of the testing procedures were explained, and written informed consent was obtained. All procedures of this study were carried out in accordance with approval from the local University's Institutional Review Board (IRB protocol \# HR-2437). 
NOT THE PUBLISHED VERSION; this is the author's final, peer-reviewed manuscript. The published version may be accessed by following the link in the citation at the bottom of the page.

\section{Procedures}

\section{Hip Strength Measures}

Maximal isometric hip strength was tested for the hip abductor and external rotator muscle groups using a hand-held dynamometer (Lafayette Manual Muscle Tester model 01163; Lafayette Instrument Company; Lafayette, IN). The hip abductor muscle group was tested in the side-lying position with the test hip placed in the neutral position, which was defined as $0^{\circ}$ of rotation in any plane (Figure $1 \mathrm{a}$ ). The bottom leg was flexed slightly at the knee and hip in order to assist with maintaining stability during the test. Pillows were placed between the legs of the subject in order to maintain a neutral position of the hip in the frontal plane during the testing. The frontal plane hip angle was measured using a standard long arm goniometer (Sammons Preston $\left.{ }^{\mathrm{T}} \mathrm{M}\right)$ to ensure that the hip was in neutral rotation during the test. The hand-held dynamometer was placed one inch proximal to the lateral epicondyle of the femur in a perpendicular position to the thigh and was secured to the leg using a custom foam cutout and canvas strap. The strap was secured around the undersurface of the athletic table in order to prevent slippage during testing. The dynamometer was stabilized by a hand of the examiner to prevent tilt that could lead to non-perpendicular force production. The subject was instructed to press the leg upward toward the ceiling without rotating the pelvis or limb. The subject was instructed to press upward with maximal effort, but to avoid a rapid or jerky movement, and to slowly build to maximal effort over a 5 second period. 

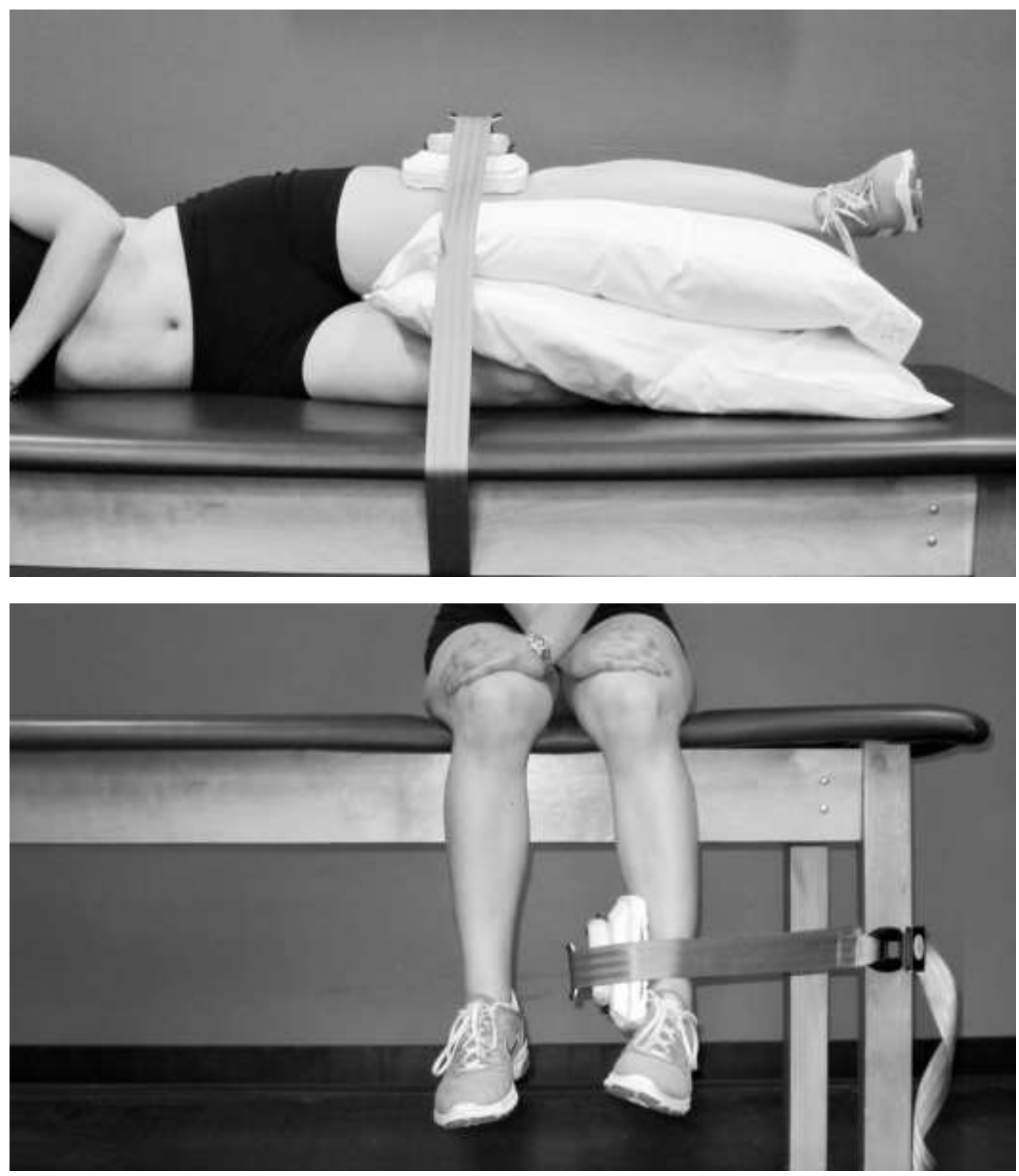

Figure 1: Isometric hip strength testing set up

a) Hip abduction was tested with the subject positioned in side lying with the hip and pelvis in neutral rotation in all planes. Muscle torque was calculated as a product of the force $(\mathrm{N})$ and femur length $(\mathrm{m})$ was normalized to body weight $(\mathrm{kg})$.

b) Hip external rotation was tested with the subject in the seated position with the hip in 90 degrees of flexion and neutral frontal and transverse plane rotation. Muscle torque was calculated as a product of the force $(\mathrm{N})$ and femur length $(\mathrm{m})$ was normalized to body weight $(\mathrm{kg})$.

\section{The hip external rotators were tested in a seated position with} the hip placed in neutral $\left(0^{\circ}\right)$ frontal and transverse plane rotation

Journal of Strength and Conditioning Research, Vol 30, No. 1 (January 2016): pg. 282-291. DOI. This article is @ Lippincott Williams \& Wilkins, Inc. and permission has been granted for this version to appear in e-Publications@Marquette. Lippincott Williams \& Wilkins, Inc. does not grant permission for this article to be further copied/distributed or hosted elsewhere without the express permission from Lippincott Williams \& Wilkins, Inc. 
(Figure $1 \mathrm{~b}$ ). The dynamometer was placed one inch proximal to the medial malleolus of the ankle and secured to the leg using a custom foam pad and canvas strap that was attached to an athletic table. The subject was instructed to sit up right with the arms crossed and hands on each contralateral thigh to prevent flexing the hips or leaning backward during the testing. The subject was instructed to rotate the leg inward while maintaining the thigh in contact with the table. The subject was instructed to press into the strap, but to avoid a rapid or jerky movement in order to slowly build to maximal effort over a 5 second period. Maximal hip abductor and external rotator isometric torques were calculated as the product of the respective segment length (i.e. fixed external moment arm) and the isometric force measured with the hand-held dynamometer, and was then subsequently normalized to individual body weight $(\mathrm{N} \cdot \mathrm{m} / \mathrm{kg})$.

\section{Unanticipated Single-Leg Landing and Cutting Tasks}

Subjects were required to perform three different types of unanticipated single-leg landing tasks that consisted of either a:1) single leg land- and- hold 2) single leg- land -and -side - cut or 3) single leg- land and-forward run. Each subject performed between three to five successful trials of each unanticipated single-leg landing and cutting task. Prior to performing the unanticipated tasks the height and distance of the box from the force plates were normalized for each subject. The box height was normalized by having each subject first perform five maximum vertical jumps while in a position with the hands on the hips and elbows bowed out (i.e. akimbo). An x$y$ plot of the right PSIS marker position vs. time from the third vertical jump trial was created using Vicon Nexus software 1.8.2 (Vicon Motion Systems Ltd.). The distance between the initial position of the right PSIS marker during standing and the position of the marker at the maximum vertical jump height was used to normalize the box height to each subject. The rationale for this normalization was that this height would represent the maximum height an individual athlete would land from during competition. The distance of the box from the force plate was normalized to the subject's maximal single-leg jump distance, which was determined by having the subject stand on the right lower extremity in the middle of the force plate and perform a forward single-leg jump onto the left lower extremity. The distance from the edge of the force plate to the front of the athletic shoe of the 
subject was measured. The front edge of the box was placed at this distance for the unanticipated single-leg landing and cutting tasks.

All single-leg landing tasks required subjects to jump off the box and land on the force plate with one leg, and stabilize their body during the landing without touching the opposite foot to the ground or taking a step. The single leg land-and-hold task required subjects to jump off the box and stick the landing while establishing stability as quick as possible. The land-and side cut task required subjects jump off of the box, land on the force plate, and immediately perform a 90 degree lateral cut. The single leg land-and-forward run task required the subject to jump off of the box, land on the force plate and then immediately run forward after the landing. The subjects were instructed to perform the running and cutting tasks without hesitation after landing on the plate. The tasks were performed randomly with the use of a custom LabVIEW program (National Instruments, 2013) that was interfaced with a pressure switch mat placed on the top of the box. Once participants broke contact with the switch mat after jumping off, the program displayed either a red light (single-legland), right arrow (land - and - side cut) or forward arrow (land- andforward run) on a large TV screen in front of the subject. The take-off leg for all unanticipated tasks was non-dominant leg, such that the landing leg was always the dominant leg, which was defined as the leg with which one would kick a ball (Figure 2). 
NOT THE PUBLISHED VERSION; this is the author's final, peer-reviewed manuscript. The published version may be accessed by following the link in the citation at the bottom of the page.

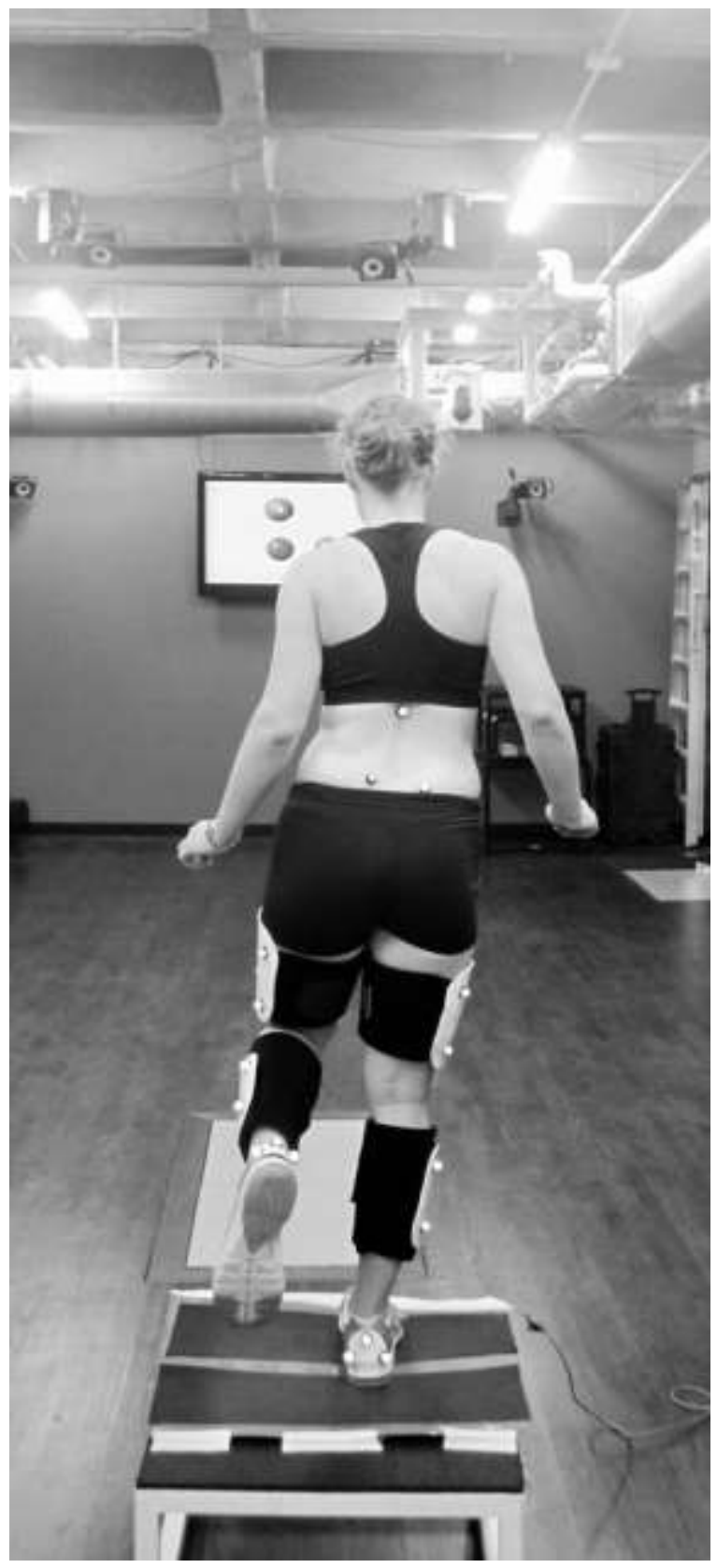

Figure 2: Starting position for the movement and cutting tasks. The movement cue on the screen in front of the subject was triggered once they left the mat which directed the subject to perform one of three landing or cutting tasks.

\section{Data Acquisition}

\section{A 14-camera motion analysis system (Vicon Motion Systems} Ltd.) was used to record kinematic data at a rate of $120 \mathrm{~Hz}$. Kinetic data were collected with an AMTI force plate (AMTI Corp. Watertown,

Journal of Strength and Conditioning Research, Vol 30, No. 1 (January 2016): pg. 282-291. DOI. This article is (C Lippincott Williams \& Wilkins, Inc. and permission has been granted for this version to appear in e-Publications@Marquette. Lippincott Williams \& Wilkins, Inc. does not grant permission for this article to be further copied/distributed or hosted elsewhere without the express permission from Lippincott Williams \& Wilkins, Inc. 
MA) at $960 \mathrm{~Hz}$. The three-dimensional positions of 23 retro-reflective markers were recorded during each task. These markers were attached to the anatomical landmarks of C7 spinous process, T10 spinous processes, sternum, and bilaterally over the PSIS, ASIS, iliac crests, greater trochanters, medial and lateral knee joint lines, medial and lateral malleoli, and first and fifth metatarsal heads. Marker clusters, consisting of four markers attached to a plastic plate fixed to a Velcro strap, were also attached to the bilateral thighs and shanks. ${ }^{13}$ In addition, clusters, of three markers attached to a plastic plate, were fixed directly to both heels. ${ }^{13}$ A standing trial in a static position was used to individualize marker position and calculate joint centers and segments positions for each individual subject during all subsequent movement testing.

\section{Data Processing}

A $4^{\text {th }}$ order, low- pass Butterworth filter with a cutoff frequency of $12 \mathrm{~Hz}$ was used to smooth the kinematic and kinetic data in Visual 3D (C-Motion, Inc, Rockville, MD). ${ }^{6,8}$ A local coordinate system was then used to define the model segments for the pelvis, thigh, shank, and foot based on marker position over the anatomical landmarks on the segments. A joint coordinate system approach was used to determine the angles of the hip, knee, and ankle. ${ }^{9,14}$ An inverse dynamics approach was used to calculate the net internal joint moments $(\mathrm{N} \cdot \mathrm{m})$ using the ground reaction force data and segmental kinematic data. ${ }^{18,28}$ Net internal joint moments were calculated in the distal relative to proximal segments coordinate system.

The variables of interest were the three-dimensional hip and knee joint angle excursions and peak joint moments during the landing phase of each unanticipated task. The landing phase was defined as the time period between the point of initial contact and the peak knee flexion angle. Initial ground contact was defined as when the vertical ground reaction force vector was greater than $30 \mathrm{~N}$. Joint excursion was defined as the difference between the joint angle at initial contact and the maximum joint angle during the landing phase. For simplification, all data are represented from the perspective of a right lower extremity with the direction of the data consistent with the right hand rule.

Journal of Strength and Conditioning Research, Vol 30, No. 1 (January 2016): pg. 282-291. DOI. This article is (C) Lippincott Williams \& Wilkins, Inc. and permission has been granted for this version to appear in e-Publications@Marquette. Lippincott Williams \& Wilkins, Inc. does not grant permission for this article to be further copied/distributed or hosted elsewhere without the express permission from Lippincott Williams \& Wilkins, Inc 
NOT THE PUBLISHED VERSION; this is the author's final, peer-reviewed manuscript. The published version may be accessed by following the link in the citation at the bottom of the page.

\section{Statistical Analysis}

Initially, the assumptions of parametric statistical tests were checked through the evaluation of Q-Q plots, the Shapiro-Wilk test for normality, and standardized residual plots for homoscedasticity for all variables. All data were determined to meet the assumptions for parametric testing. Next, Pearson's correlation coefficients were calculated to determine the associations between the independent variables (hip abduction and external rotation torque) and the dependent variables (hip and knee excursion and peak hip and knee moments in all planes). Statistical significance was set a priori at $\mathrm{a}=$ 0.05. All statistical analyses were performed in SPSS (IBM, Chicago, IL).

\section{Results}

Prior to the correlational analysis, a MANOVA was performed to determine if mean differences exist on the dependent variables among the three unanticipated tasks (i.e. land-and- hold task; land-and-cut task; land-and-forward run task). The results demonstrated no significant difference between the tasks for any of the dependent variables $(F=1.095, p=.376)$. Therefore, it was decided that the means of the kinematic and kinetic variables from each of the three tasks should be combined for final analysis (Table 1). The values presented in table 1 represent the three-task averages. The ensemble average for female athletes hip and knee moments from initial contact to maximum knee flexion (i.e. stance phase) during a single leg unanticipated land and cut task are presented to demonstrate the overall kinetic pattern at the hip and knee during landing (Figures 3a, ,4a,4a, 5a \& b, 6a \& b). Additionally, ensemble average transverse plane kinematic patterns at the hip and knee are also presented for clarity (Figures 3b \& 4b). 
NOT THE PUBLISHED VERSION; this is the author's final, peer-reviewed manuscript. The published version may be accessed by following the link in the citation at the bottom of the page.

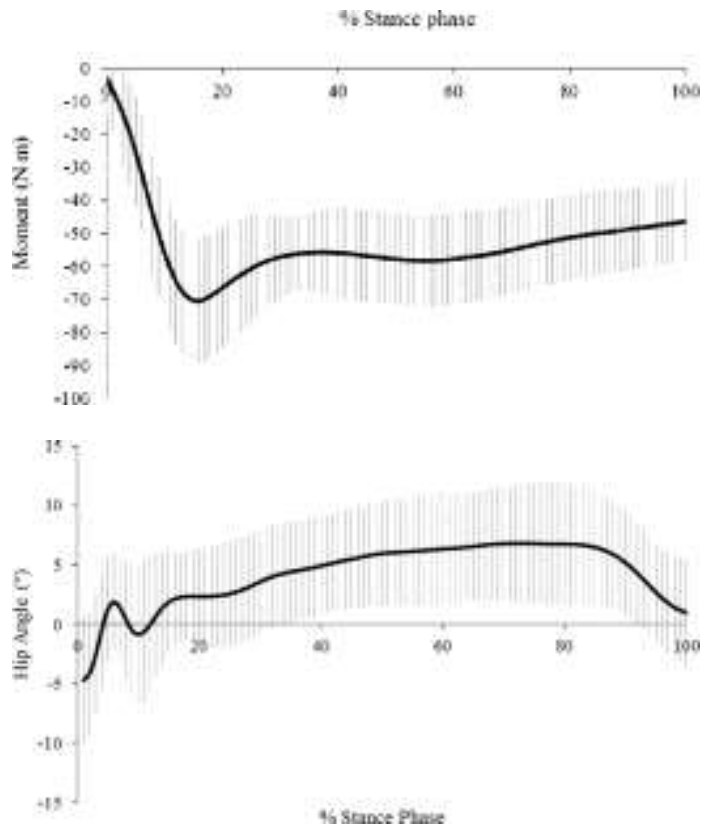

Figure 3: Hip transverse plane moments $(\mathrm{Nm})$ and angles $\left(^{\circ}\right)$

a) Ensemble average and standard deviation of transverse plane hip moments from initial contact to peak knee flexion (i.e. stance phase). Negative $(-)$ values represent external rotation and positive $(+)$ values represent internal rotation.

b) Ensemble average of transverse plane hip angles for all subjects from initial contact to peak knee flexion (i.e. stance phase). Positive values are in the direction of internal rotation and negative values are in the direction of external rotation.
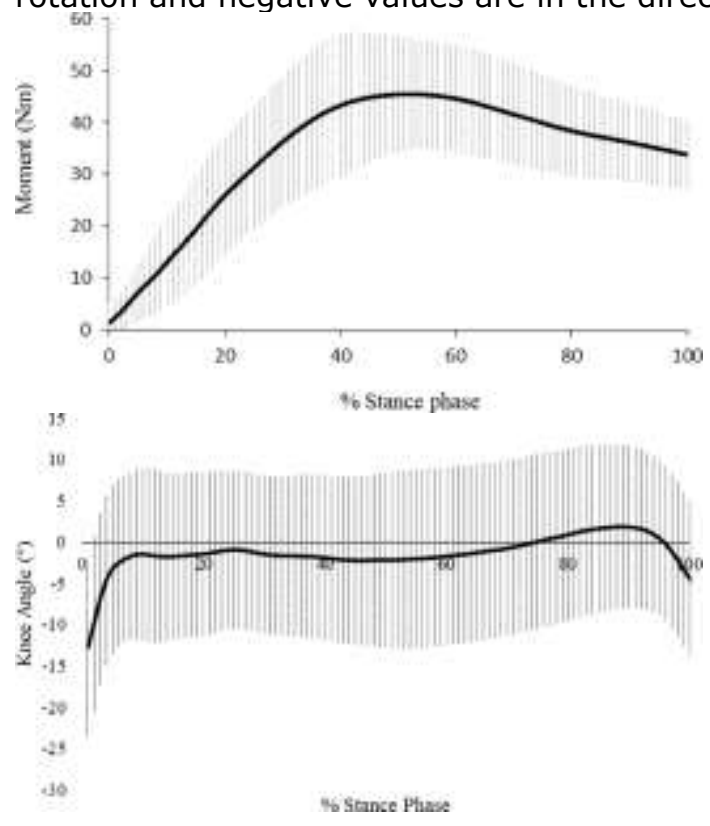

Figure 4: Knee Transverse plane moments $(\mathrm{Nm})$ and angles $\left(^{\circ}\right)$

a) Ensemble average and standard deviations for transverse plane knee moment from initial contact to peak knee flexion (i.e. stance phase). Negative $(-)$ values represent external rotation and positive $(+)$ values represent internal rotation.

Journal of Strength and Conditioning Research, Vol 30, No. 1 (January 2016): pg. 282-291. DOI. This article is (C) Lippincott Williams \& Wilkins, Inc. and permission has been granted for this version to appear in e-Publications@Marquette. Lippincott Williams \& Wilkins, Inc. does not grant permission for this article to be further copied/distributed or hosted elsewhere without the express permission from Lippincott Williams \& Wilkins, Inc. 
NOT THE PUBLISHED VERSION; this is the author's final, peer-reviewed manuscript. The published version may be accessed by following the link in the citation at the bottom of the page.

b) Ensemble average of transverse plane knee angles for all subjects from initial contact to peak knee flexion (i.e. \% landing phase). Positive values are in the direction of internal rotation and negative values are in the direction of external rotation.
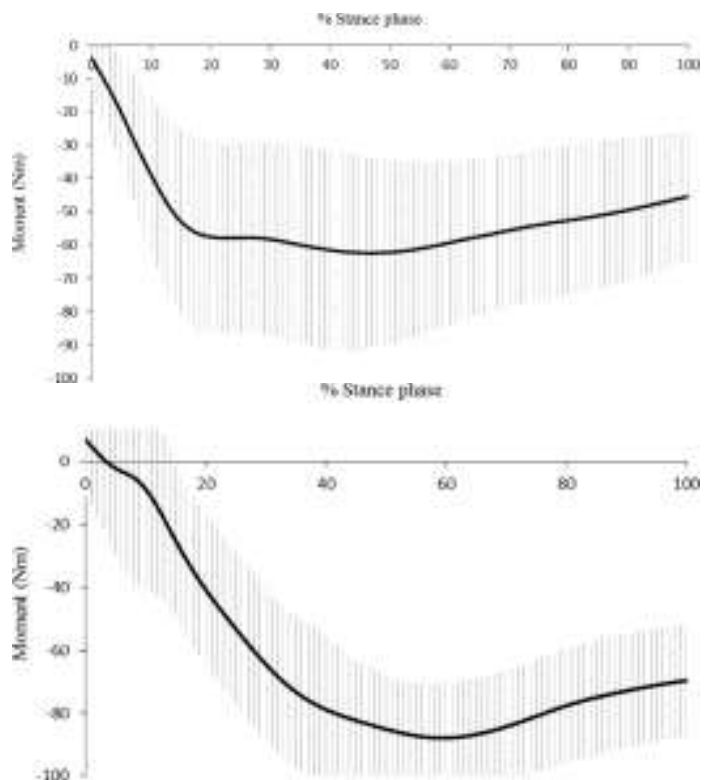

Figure 5: Ensemble average and standard deviation knee and hip frontal plane moments $(\mathrm{Nm})$

a) Knee frontal plane moment from initial contact to peak knee flexion (i.e. stance phase). Negative $(-)$ values represent abduction and positive $(+)$ values represent adduction.

b) Hip frontal plane moment from initial contact to peak knee flexion (i.e. stance phase). Negative $(-)$ values represent abduction and positive $(+)$ values represent adduction.

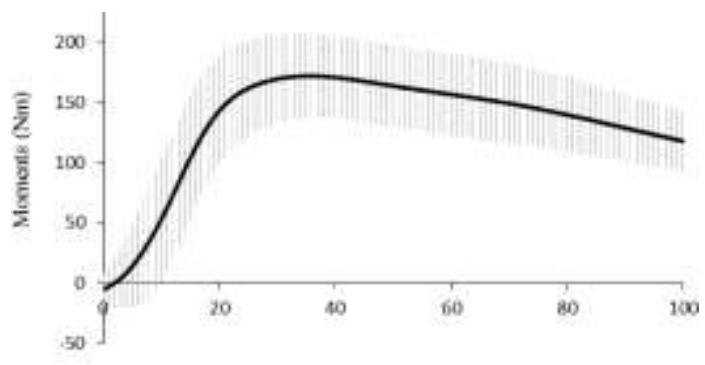

So Stubee phase

Figure 6: Ensemble average and standard deviations of knee and hip sagittal plane moments $(\mathrm{Nm})$

a) Knee sagittal plane moment from initial contact to peak knee flexion (i.e. stance phase). Negative values $(-)$ represent knee flexion and positive $(+)$ values represent knee extension.

b) Hip sagittal plane moments from initial contact to peak knee flexion (i.e. stance phase). Negative (-) values represent extension and positive values (+) represent flexion. 
NOT THE PUBLISHED VERSION; this is the author's final, peer-reviewed manuscript. The published version may be accessed by following the link in the citation at the bottom of the page.

Table 1: Mean (SD) hip strength $(\mathrm{Nm} / \mathrm{kg})$ and knee/hip kinematics $\left(^{\circ}\right)$ and kinetics $(\mathrm{Nm})$

Independent Variables

Hip ER torque $(\mathrm{N} \cdot \mathrm{m} / \mathrm{kg})$

Hip abduction torque $(\mathrm{N} \cdot \mathrm{m} / \mathrm{kg})$

Dependent Variables

Sagittal knee excursion

Frontal knee excursion

Transverse knee excursion

Sagittal hip excursion

Frontal hip excursion

Transverse hip excursion

Peak sagittal knee moments

Peak frontal knee moments

Peak transverse knee moments

Peak sagittal hip moments

Peak frontal hip moments

Peak transverse hip moments
Mean (SD)

$0.41(0.12)$

$1.72(0.49)$

$44.6(7.1)$

$2.1(2.5)$

$-15.4(3.9)$

$-26.2(5.3)$

$23.4(6.6)$

$-12.6(4.3)$

$176.5(33.3)$

$-3.3(9.8)$

$47.7(11.3)$

$-15.5(24.9)$

$17.2(22.4)$

$-77.3(16.4)$

Significant correlations were found between hip external rotator strength and transverse plane joint moments at the hip and knee (Table 2). Specifically, hip external rotator strength was significantly correlated with the peak hip external rotation moment and peak knee internal rotation moment. Frontal plane hip excursion and transverse plane knee excursion were also significantly associated with hip external rotator strength (Table 2). A statistical trend was also present for the correlation between hip external rotator strength and peak hip abduction moment (Table 2). Hip abductor strength was not significantly correlated with any other biomechanical variables (Table 2).

Table 2: Pearson's $r$ between hip strength and knee/hip kinematic and kinetic variables

Sagittal knee excursion

Frontal knee excursion

Transverse knee excursion

Sagittal hip excursion

Frontal hip excursion

Transverse hip excursion

Peak sagittal knee moments

\section{Abduction p-value External rotation p-value}

$\begin{array}{cccc}.14 & .53 & .15 & .49 \\ .04 & .85 & -.21 & .32 \\ .02 & .95 & -.56 & .004 \\ .01 & .97 & .02 & .93 \\ .20 & .36 & .49 & .017 \\ -.16 & .48 & .11 & .62 \\ .23 & .30 & .14 & .53\end{array}$

Journal of Strength and Conditioning Research, Vol 30, No. 1 (January 2016): pg. 282-291. DOI. This article is (C) Lippincott Williams \& Wilkins, Inc. and permission has been granted for this version to appear in e-Publications@Marquette. Lippincott Williams \& Wilkins, Inc. does not grant permission for this article to be further copied/distributed or hosted elsewhere without the express permission from Lippincott Williams \& Wilkins, Inc. 
NOT THE PUBLISHED VERSION; this is the author's final, peer-reviewed manuscript. The published version may be accessed by following the link in the citation at the bottom of the page.

\begin{tabular}{lcccc} 
& \multicolumn{4}{c}{ Abduction $\boldsymbol{p}$-value External rotation $\boldsymbol{p}$-value } \\
Peak frontal knee moments & .08 & .71 & .06 & .79 \\
Peak transverse knee moment & .20 & .35 & .42 & .04 \\
Peak sagittal hip moments & -.16 & .47 & -.17 & .44 \\
Peak frontal hip moments & .34 & .12 & .39 & .06 \\
Peak transverse hip moment & -.36 & .09 & -.48 & .02
\end{tabular}

Bold text indicates significant correlation

\section{Discussion}

The purpose of this study was to determine the association between hip strength and lower extremity kinematics and kinetics during unanticipated single-leg landing and cutting tasks in female athletes. The most important findings of the current study were the associations between hip external rotator strength and hip and knee kinetics during unanticipated single-leg landing and cutting tasks. Specifically, female soccer players with greater hip external rotator strength demonstrated greater peak hip external rotation and abduction moments and peak knee internal rotation moments during landing. In addition, females with greater hip external rotator strength demonstrated greater hip frontal plane excursion and knee transverse plane excursion during unanticipated movement tasks. To our surprise, the current study did not reveal any associations between hip abductor strength and any of the biomechanical variables. Regardless, these results partially support our hypothesis that greater hip strength would be associated with better lower extremity kinematic and kinetics during unanticipated single-leg landing and cutting tasks. Therefore the practical importance of the results, which link hip external rotator strength with hip and knee kinetics during unanticipated single-leg landing and cutting, provides support for the role of hip strength in the dynamic control of the lower extremity during unanticipated landing tasks.

The results of the current study showed a moderate correlation $(r=-.48)$ between hip external rotator strength and peak hip external rotation moments during unanticipated single leg landing and cutting tasks in female athletes. Given that hip external rotation moments are negative by convention, the correlation indicates that greater hip external rotation moments are associated with greater hip external rotator strength. The association between hip external rotator strength 
and hip external moments suggests that greater hip strength may promote better dynamic control of the femur and/or pelvis during the landing phase of an unanticipated task. The hip kinematic and kinetic patterns in the transverse plane were occurring in opposite directions, which indicated that hip internal rotation motions were being decelerated by external rotation moments, thereby controlling a rotational aspect of the purported deleterious dynamic valgus. ${ }^{15}$ Lawrence and colleagues also showed an association between hip external rotator strength and better dynamic lower extremity control during single leg landings. ${ }^{20}$ These authors demonstrated that females with greater hip external strength experienced smaller ground reaction forces and mean external knee valgus moments. They concluded that weak hip musculature may lead to increased risk of deleterious landing mechanics consistent with non-contact ACL injury. ${ }^{20}$ It therefore seems rational to argue that female athletes with greater hip external rotator strength are able to better control aspects of dynamic valgus during single leg unanticipated landing tasks thereby lessening the risk of non-contact ACL injury.

A moderate correlation $(r=.42)$ between hip external rotator strength and knee internal rotation moments during unanticipated landing and cutting tasks was also found. Additionally, a moderate negative correlation ( $r=-.56$ ) was also found between hip external rotator strength and transverse plane knee excursion. Our transverse plane knee moment findings are consistent with previous investigations that utilized a similar unanticipated movement task. ${ }^{6}$ Similar to our observations at the hip joint, the mean transverse kinematic pattern of the knee indicates that females internally rotate at initial contact and then rapidly stabilize the knee in a near neutral transverse plane position. Our findings indicate that the knee and hip were both in an externally rotated position at initial contact, which, supports the fact that these females athletes landed with the lower extremity in neutral alignment in the transverse plane. The neutral lower extremity alignment at initial contact and the rapid stabilization of the knee in the transverse plane after initial contact support that hip external rotator strength may also play a role in dynamic transverse plane control at the knee during unanticipated landing and cutting tasks. 
Based on the fact that the correlations in the current study were between hip external rotation strength and hip and knee kinetic variables, we believe that the gluteus maximus was predominantly responsible for the dynamic control of the unanticipated landing and cutting tasks. The hip sagittal plane kinetic pattern indicates a strong hip extension moment during the landing phase and the hip transverse plane kinetic pattern resembles a similar shape to the sagittal plane moment pattern. The gluteus maximus muscle exhibits the greatest force generating capacity of all hip muscles and is commonly recruited during tasks that require deceleration of the center of mass or propulsion of the body mass forward and upward such as during walking and vertical jumping. ${ }^{24,32}$ Moreover, the gluteus maximus is a strong hip external rotator, and we therefore postulate that its role in hip external rotator torque production is the reason that hip and knee kinetics during an unanticipated landing and cutting task were most closely associated with this measure. Although muscle activity was not quantified in the current study and the exact mechanism in which the gluteus maximus may control aspects of dynamic valgus is not fully understood, it seems that the hip musculature does play an important role in dynamic control and should be addressed in training and rehabilitation programs for athletes.

The current study also found that females with greater hip external rotator strength exhibited greater frontal plane hip excursion into the direction of adduction (i.e. dynamic valgus) during an unanticipated single leg land and cut task. The current results are similar to another research group who found significant correlation between hip external rotation strength and frontal plane knee excursion (i.e. knee valgus) during a drop jump landing. ${ }^{5}$ Bandholm (2011) and colleagues suggest that, over time, repeatedly landing in greater knee valgus positions leads to movement pattern "adaptation" that is related to gains in hip strength because of the repeated activation of the hip external rotators (i.e gluteus maximus) as part of this control strategy. ${ }^{5}$ In the current study, the contralateral pelvis was elevated at initial contact (i.e. relative hip abduction) and moved into a dropped position (i.e. relative hip adduction) throughout the landing phase, which results in frontal plane hip excursion in the direction of adduction. The control of this pattern can be explained by the current studies statistical trend between hip external rotator strength and hip abduction moments during the single leg unanticipated land and cut

Journal of Strength and Conditioning Research, Vol 30, No. 1 (January 2016): pg. 282-291. DOI. This article is (C Lippincott Williams \& Wilkins, Inc. and permission has been granted for this version to appear in e-Publications@Marquette. Lippincott Williams \& Wilkins, Inc. does not grant permission for this article to be further copied/distributed or hosted elsewhere without the express permission from Lippincott Williams \& Wilkins, Inc. 
tasks. When the hip frontal plane kinematics and kinetic patterns are considered in combination it seems that hip frontal plane excursion in the direction of adduction was being controlled by an oppositely directed hip abduction moment. Therefore, the relationship between hip external rotator strength and the frontal plane dynamic control pattern at the hip in current study support the movement "adaptation" previously described by Bandholm. ${ }^{5}$

There are several limitations to the current study that must be taken into consideration. The sample in the current study involved high level female athletes, which may limit the generalizability of the results to other populations. In addition, the results from a crosssectional study with correlational analysis cannot be used to determine causation between measures of hip strength and landing mechanics. Future prospective and longitudinal research could provide data that establishes stronger links between hip strength and landing mechanics. ${ }^{30}$ The use of electromyography to quantify muscle activation patterns may also provide valuable information into the neuromuscular strategies used during a single leg unanticipated task. ${ }^{16}$ Additionally, hip abductor strength was tested isometrically in an open chain position, whereas the tasks of interest were closed chain movements. Perhaps testing the hip abductors and external rotators in a closed chain position would provide a more functional approach to assessing muscle strength for landing tasks. ${ }^{31}$ Finally, we acknowledge the difference between lab-based testing and game situations, even if both are unanticipated.

\section{Practical Applications}

The current study demonstrates that greater hip external rotator strength was associated with greater peak hip external rotation and abduction moments, greater peak knee internal rotation moments, and greater hip frontal plane excursion during unanticipated single-leg landing tasks. The kinetic and kinematic patterns demonstrated in the current study support that hip external rotator strength may play a role in the control of dynamic valgus during unanticipated landing and cutting. Therefore, practitioners should consider implementing hip muscle strengthening into training programs for athletes that participate in sports that require landing and cutting. 
NOT THE PUBLISHED VERSION; this is the author's final, peer-reviewed manuscript. The published version may be accessed by following the link in the citation at the bottom of the page.

\section{Acknowledgments}

The authors would like to acknowledge support through the National Center for Advancing Translational Sciences, National Institutes of Health, Grant Number 8UL1TR000055.

\section{References}

${ }^{1}$ Agel J, Klossner D. Epidemiologic review of collegiate ACL injury rates across 14 sports: National Collegiate Athletic Association injury surveillance system data 2004-05 through 2011-12. Br J Sports Med. 2014;48:560.

2 Alentorn-Geli E, Myer GD, Silvers HJ, Samitier G, Romero D, et al. Prevention of non-contact anterior cruciate ligament injuries in soccer players. Part 1: mechanisms of injury and underlying risk factors. Knee Surg Sports Traumatol Arthrosc. 2009;17:705-729.

${ }^{3}$ Arendt E, Dick R. Knee injury patterns among men and women in collegiate basketball and soccer: NCAA data and review literature. Am. J Sports Med. 1995;23:694-701.

${ }^{4}$ Baldon R, Lobato D, Carvalho L, Santiago P, Benze B, Serrao F. Relationship between eccentric hip torque and lower limb kinematics: gender differences. J Appl Biomech. 2011;27:223-232.

${ }^{5}$ Bandholm T, Thorburg K, Andersson E, Larsen T, Toftdahl M, Bencke J, Holmich $P$. Increased external hip rotation strength relates to reduced dynamic knee control in females: paradox or adaptation? Scand J Med Sci Sports. 2011;21:e215-e221.

${ }^{6}$ Beiser TF, Lloyd DG, Ackland TR, Cochrane JL. Anticipatory effects on knee joint loading during running and cutting maneuvers. Med Sci Sports Exerc. 2001;33:1176-1181.

7 Bolgla LA, Malone TR, Umberger BR, Uhl TL. Hip strength and hip and knee kinematics during stair descent in females with and without patellofemoral pain syndrome. J Orthop Sports Phys Ther. 2008;38:12-18.

${ }^{8}$ Brown TN, Palmieri-Smith R, McLean SG. Sex and limb differences in hip and knee kinematics and kinetics during anticipated and unanticipated jump landings: implications for anterior cruciate ligament injury. $\mathrm{Br} \mathrm{J}$ Sports Med. 2009;43:1049-1056.

${ }^{9}$ Cole GK, Nigg BM, Ronsky JL, Yeadon MR. Application of the Joint Coordinate System to Three-Dimensional Joint Attitude and Movement Representation: A Standardization Proposal. J Biomech Eng. $1993 ; 115: 344-349$.

Journal of Strength and Conditioning Research, Vol 30, No. 1 (January 2016): pg. 282-291. DOI. This article is (C) Lippincott Williams \& Wilkins, Inc. and permission has been granted for this version to appear in e-Publications@Marquette. Lippincott Williams \& Wilkins, Inc. does not grant permission for this article to be further copied/distributed or hosted elsewhere without the express permission from Lippincott Williams \& Wilkins, Inc. 
NOT THE PUBLISHED VERSION; this is the author's final, peer-reviewed manuscript. The published version may be accessed by following the link in the citation at the bottom of the page.

${ }^{10}$ Delp SL, Hess WE, Hungerford DA, Jones LC. Variation in rotation moments with hip flexion. J Biomech. 32:493-501.

${ }^{11}$ Decker MJ, Torry MR, Wyland DJ, Sterett WI, Steadman R. Gender differences in lower extremity kinematics, kinetics, and energy absorption during landing. Clin. Biomech. 2003;18:662-669.

${ }^{12}$ Faul F, Erdefelder E, Buchner A, Lang AG. Statistical power analysis using G*Power 3.1: Tests for correlation and regression analyses. Behav Res Methods. 2009;41:1149-1160.

${ }^{13}$ Geiser CF, O'Connor KM, Earl JE. Effects of isolated hip abductor fatigue on frontal plane knee mechanics. Med. Sci. Sports Exerc. 2010;42:535545.

${ }^{14}$ Grood ES, Suntay WJ. A joint coordinate system for the clinical description of three-dimensional motions: application to the knee. J. Biomech Eng. 1983; 105:136-144.

${ }^{15}$ Hewett TE, Myer GD, Ford KR, et al. Biomechanical measures of neuromuscular control and valgus loading of the knee predict anterior cruciate injury risk in female athletes: a prospective study. Am J Sports Med. 2005;33:492-501.

${ }^{16}$ Homan KJ, Norcross MF, Goerger BM, Blackburn JT. The influence of hip strength on gluteal activity and lower extremity kinematics. $J$ Electromyography Kinesiol. 2013;23:411-415.

17 Jacobs CA, UhI TL, Mattacola CG, Shapiro R, Rayens WS. Hip abductor function and lower extremity landing kinematics: sex differences. $J$ Athl Train. 2007;42:76-83.

${ }^{18}$ Kabada MP, Ramakrishnan, Wooten ME. Measurement of lower extremity kinematics during level walking. J Orthop Res. 1990;8:383-392.

${ }^{19}$ Kernozek TW, Torry MR, Iwasaki M. Gender differences in lower extremity landing mechanics caused by neuromuscular fatigue. Am J Sports Med. 2008;36:554-565.

${ }^{20}$ Lawrence RK, Kernozek TW, Miller EJ, Torry MR, Reutmann P. Influences of hip external rotation strength on knee mechanics during single-leg drop landings in females. Clin Biomech. 2008;23:806-813.

${ }^{21}$ Leetun DT, Ireland ML, Willson JD, Ballantyne BT, Davis IM. Core stability measures as risk factors for lower extremity injury in athletes. Med Sci Sports Exerc. 2004;36:926-934.

22 McLean SG. The ACL injury enigma: we can't prevent what we don't understand. J Athl Train. 2008;43:538-540.

${ }^{23}$ McLean SG, Huang X, van den Bogert AJ. Association between lower extremity posture at contact and peak knee valgus moment during sidestepping: implications for ACL injury. Clin Biomech. 2005;20:863870.

${ }^{24}$ Neumann DA. Kinesiology of the hip: a focus on muscular actions. J Orthop Sports Phys Ther. 2010;40:82-94.

Journal of Strength and Conditioning Research, Vol 30, No. 1 (January 2016): pg. 282-291. DOI. This article is (C) Lippincott Williams \& Wilkins, Inc. and permission has been granted for this version to appear in e-Publications@Marquette. Lippincott Williams \& Wilkins, Inc. does not grant permission for this article to be further copied/distributed or hosted elsewhere without the express permission from Lippincott Williams \& Wilkins, Inc 
NOT THE PUBLISHED VERSION; this is the author's final, peer-reviewed manuscript. The published version may be accessed by following the link in the citation at the bottom of the page.

25 Pollard CD, Sigward SM, Powers CM. Gender differences in hip joint kinematics and kinetics during side-step cutting maneuver. Clin $\mathrm{J}$ Sports Med. 2007;17:38-42.

${ }^{26}$ Pollard CD, Sigward SM, Powers CM. Limited hip and knee flexion during landing is associated with increased frontal plane knee motion and moments. Clin Biomech. 2010;25

27 Powers CM. The influence of abnormal hip mechanics on knee injury: a biomechanical perspective. J Orthop Sports Phys Ther. 2010;40:4251.

${ }^{28}$ Schache AG, Baker R. On the expression of joint moments during gait. Gait and Posture. 2008;25:440-452.

${ }^{29}$ Sigward SM, Powers CM. The influence of gender on knee kinematics, kinetics, and muscle activation patterns during side-step cutting. Clin Biomech. 2006;21:41-48.

30 Stearns KM, Powers CM. Improvement in hip muscle performance results in increased use of the hip extensors and abductors during a landing task. Am J Sports Med. 2014

${ }^{31}$ Szu-Ping L, Powers CM. Description of a weight bearing method for assessing hip abductor and external rotator muscle performance. $J$ Orthop Sports Phys Ther. 2013;43:392-397.

32 Thomas C, Jones PA, Rothwell J, Chiang CY, Comfort P. An investigation into the relationship between maximum isometric strength and vertical jump performance. J Strength Cond Res. 2015

Journal of Strength and Conditioning Research, Vol 30, No. 1 (January 2016): pg. 282-291. DOI. This article is (C) Lippincott Williams \& Wilkins, Inc. and permission has been granted for this version to appear in e-Publications@Marquette. Lippincott Williams \& Wilkins, Inc. does not grant permission for this article to be further copied/distributed or hosted elsewhere without the express permission from Lippincott Williams \& Wilkins, Inc. 